Revista Brasileira de Agricultura Irrigada v.14, no .3, p. 4097 - 4105, 2020

ISSN 1982-7679 (On-line)

Fortaleza, CE, INOVAGRI - http://www.inovagri.org.br

DOI: $10.7127 /$ rbai.v14n101171

Protocolo 1171.20 - 22/06/2020 Aprovado em 29/10/2020

\title{
BALANÇO HÍDRICO DE UMA ÁREA PILOTO SOB CULTIVO DE PASTAGEM Megathyrsus maximus NO CERRADO MARANHENSE
}

Thalys Vasconcelos Lima ${ }^{1}$, Nítalo André Farias Machado ${ }^{2}$, Hosana Aguiar Freitas de Andrade ${ }^{3}$, Rafaela Leopoldina Silva Nunes ${ }^{1}$, Geovane Barbosa Reinaldo Costa ${ }^{4}$, Raissa Rachel Salustriano da Silva-Matos ${ }^{5}$

\section{RESUMO}

O balanço hídrico climatológico (BHC) pode servir como uma ferramenta para maior sustentabilidade no uso de solo de pastagens cultivadas. Nesse sentido, objetivou-se determinar o BHC para uma área piloto sob cultivo convencional de pastagem mombaça (Megathyrsus maximus) no cerrado maranhense. Foram coletados dados da temperatura $\left({ }^{\circ} \mathrm{C}\right)$, umidade relativa $(\%)$ e velocidade do vento $\left(\mathrm{m} \mathrm{s}^{-1}\right)$ usando vinte miniestações meteorológicas equipadas com anemômetros e pluviômetros digitais. Foram calculados os valores médios diários e mensais em uma série histórica de três anos consecutivos. O BHC foi estimado pelo método de Thornthwaite e Mather Os dados foram analisados por testes paramétrico (Tukey) ou não-paramétrico (Kruskal-Wallis), adotando o nível de significância de $\mathrm{P}<0.05$. Os resultados mostraram evidências de uma distribuição sazonal das chuvas com duas estações climáticas definidas, sendo o período chuvoso de novembro a abril, onde há maior biomassa de mombaça disponível, nos meses de maio a outubro (período seco), deve adotar estratégias alimentares alternativas, como fenação, silagem ou confinamento. A precipitação pluviométrica anual mais provável é $1174,6 \mathrm{~mm}$.

Palavras-chave: Climatologia, deficiência hídrica, mombaça, sustentabilidade.

\footnotetext{
${ }^{1}$ Granduando em Agronomia, Universidade Federal do Maranhão, BR Km 222, SN, Bairro Boa Vista, CEP:65.500-000, Chapadinha, MA, Brasil. E-mail: mano_vasconcelos@hotmail.com; rafaela12051@ hotmail.com.

${ }^{2}$ Doutorando em Engenharia Agrícola, Universidade Federal do Ceará, Av. Humberto Monte, SN, Bairro Pici, CEP: 60.440-593, Fortaleza, CE, Brasil. E-mail: nitalo-farias@ hotmail.com.

${ }^{3}$ Mestranda em Ciência do Solo, Universidade Federal do Ceará, Av. Humberto Monte, SN, Bairro Pici, CEP: 60.440593, Fortaleza, CE, Brasil. E-mail: hosana_f.andrade@hotmail.com

${ }^{4}$ Mestrando em Engenharia Agrícola, Universidade Federal do Ceará, Av. Humberto Monte, SN, Bairro Pici, CEP: 60.440-593, Fortaleza, CE, Brasil. E-mail: geovanebarbosa09@gmail.com.

${ }^{5}$ Docente em Agronomia, Universidade Federal do Maranhão, BR Km 222, SN, Bairro Boa Vista, CEP:65.500-000, Chapadinha, MA, Brasil. E-mail: raissasalustriano@yahoo.com.br.
} 


\title{
WATER BALANCE IN A PILOT AREA UNDER PASTURE CULTIVATION Megathyrsus maximus IN CERRADO MARANHENSE
}

\begin{abstract}
The climatological water balance $(\mathrm{CWB})$ can serve as a tool for greater sustainability in the use of $: \ldots$ from cultivated pastures. In this sense, the objective was to determine the CWB for a pilot area under conventional cultivation of pasture mombasa (Megathyrsus maximus) in the Savana of Maranhão. Data on temperature $\left({ }^{\circ} \mathrm{C}\right)$, relative humidity $(\%)$ and wind speed $\left(\mathrm{m} \mathrm{s}^{-1}\right)$ were collected using twenty meteorological mini stations equipped with digital anemometers and rain gauges. Average daily and monthly values were calculated over a three-year consecutive year series. CWB was estimated using the Thornthwaite and Mather method. Data were analyzed using parametric (Tukey) or non-parametric (Kruskal-Wallis) tests, adopting a significance level of $\mathrm{P}<0.05$. The results showed evidence of a seasonal distribution of rainfall with two defined climatic seasons, with the rainy period from November to April, where there is greater biomass of mombasa available, in the months of May to October (dry season), it should adopt alternative feeding strategies, such as haymaking, silage or confinement. The most likely annual rainfall is $1174.6 \mathrm{~mm}$.
\end{abstract}

Keywords: Climatology, water deficit, mombasa, sustainability.

\section{INTRODUÇÃO}

O cerrado brasileiro é considerado um dos maiores centros de produção de alimentos no mundo. Nesta região, a produção de proteína animal a partir da carne bovina vem ganhando destaque cada vez maior no cenário internacional pelo elevado potencial produtivo e qualidade (CARVALHO et al., 2014).

A principal fonte alimentar dos animais são as pastagens, que são totalmente dependentes das condições climáticas, especialmente a chuva. O capim Megathyrsus maximus cv. Mombaça veem sendo introduzido em substituição as pastagens do gênero Brachearia pelo menor grau de exigência em relação à acidez $\mathrm{e}$ fertilidade do solo (CARNEIRO et al., 2017).

Entretanto, grande parte das pastagens, seja cultivada ou nativa, encontra-se em algum estádio de degradação (ANDRADE et al., 2011). Nessa perspectiva, o estudo agroclimático pode servir como uma ferramenta para o planejamento de uso do solo, a fim de garantir um maior índice de sustentabilidade nas pastagens cultivadas, principalmente em regiões de Cerrado, que possuem baixa fertilidade natural (MATOS et al., 2014).

A disponibilidade hídrica pode ser quantificada por meio do balanço hídrico climatológico (BHC), determinando-se as épocas de deficiência e excedente hídrico, a reposição e retirada da água do solo, como também a classificação climática, e assim identificar períodos cruciais, dentro de um determinado espaço-tempo (FRANCISCO et al., 2015). Essas informações contribuem para a preparação do calendário agrícola, na tomada de decisões para o manejo sustentável das pastagens (PASSOS et al., 2016; PASSOS et al., 2017).

O BHC de área tem sido usado para otimizar a gestão e o manejo de uso de solo na Paraíba (MEDEIROS et al., 2015) e Mato Grosso (SOUZA et al., 2013), em bacias hidrográficas (MEDEIROS et al., 2013) e em municípios com potenciais agrícolas (PASSOS et al., 2017; PASSOS et al. 2016). Diante disso, objetivou-se determinar o balanço hídrico climatológico e a indicação climática para uma área piloto sob cultivo convencional de pastagem Megathyrsus maximus cv. Mombaça no cerrado maranhense. 


\section{MATERIAL E MÉTODOS}

A pesquisa foi realizada em uma área piloto sob cultivo convencional de capimMombaça (Megathyrsus maximus cv. Mombaça) em uma propriedade rural (0344’33” S, 4321'21" W com $106 \mathrm{~m}$ de altitude) do município de Chapadinha - MA (Figura 1). O clima, segundo a classificação de Köppen, é do tipo tropical quente e úmido (Aw), com temperatura média anual superior a $27{ }^{\circ} \mathrm{C}$ e precipitação pluvial média anual de 1835 mm (MARANHÃ̃, 2002).

A área piloto possuía cinco hectares, com solo classificado como Latossolo
Amarelo distrófico (SANTOS et al., 2013), com $\mathrm{pH}$ em $\mathrm{CaCl} 2=5,6$; M.O = 27,9 g.dm-3; $\mathrm{CTC}=9,97$ cmolc dm-1; V $(\%)=19,2 ;$ com textura média, formado por $45 \%$ de areia grossa, $20 \%$ de areia fina, $11 \%$ de argila e $24 \%$ de silte. Um total de vinte dataloggers HOBO U12 (Onset Computer Corporation Bourne, MA, USA), equipados com anemômetro digital AD1733, distribuídos em um espaçamento de $70 \times 70 \mathrm{~m}$ na área para coleta da temperatura do ar $\left({ }^{\circ} \mathrm{C}\right)$, umidade relativa do ar $(\%)$, temperatura de globo negro $\left({ }^{\circ} \mathrm{C}\right)$ e velocidade do vento $(\mathrm{m}$ s-1).

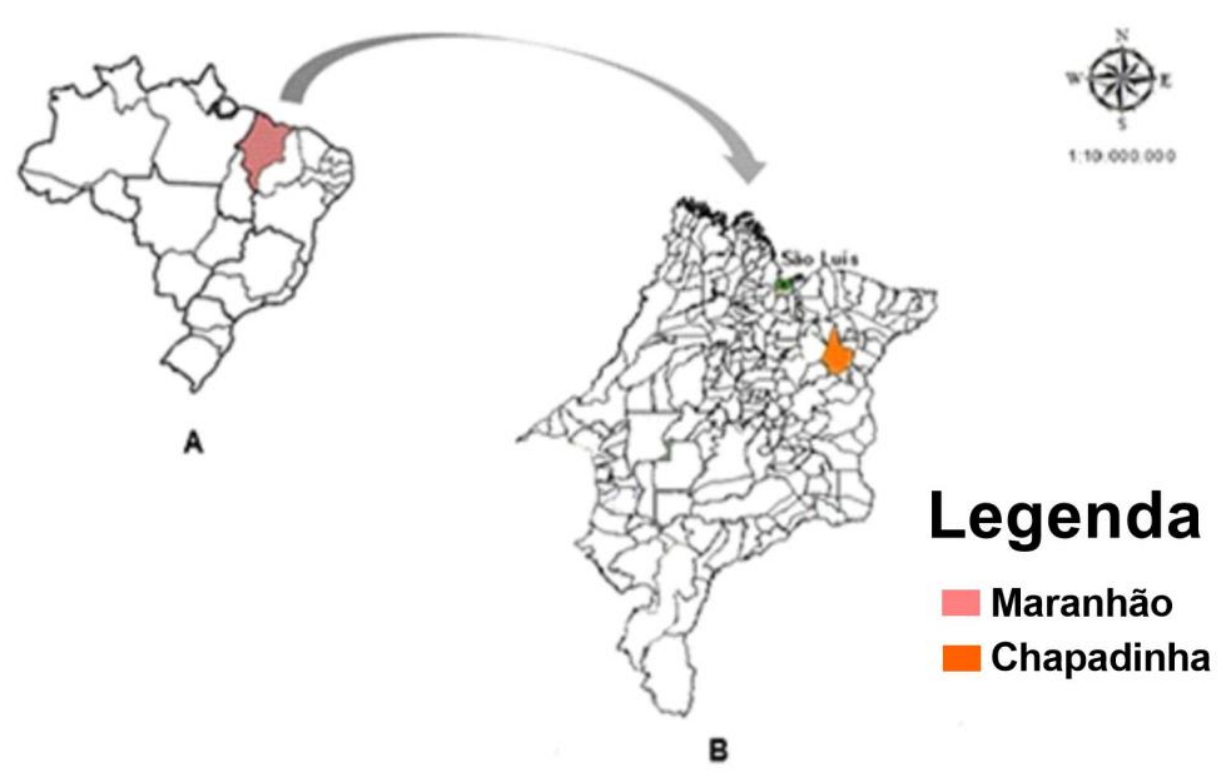

Figura 1. Localização da área experimental: mapa do Brasil com destaque para o estado do Maranhão (A), estado do Maranhão com ênfase ao município de Chapadinha (B).

A cada semana, era realizado o monitoramento dos sensores para verificar a necessidade de reposição ou manutenção. Os equipamentos foram programados para coleta de dados a cada 4 horas durante um período de 3 anos consecutivos, sendo os dados descarregados mensalmente para calculado dos valores médios diários e mensal. No mesmo período, coletou-se dados da precipitação pluviométrica diariamente, usando doze pluviômetros digitais Incoterm $^{\circledR}$
4760, distribuídos na área piloto conforme mostra a Figura 2.

O balanço hídrico climatológico (BHC) foi calculado considerando a capacidade de água disponível no solo de $100 \mathrm{~mm}$, tendo como base outros trabalhos (SOUZA et al., 2013; PASSOS et al., 2017; PASSOS et al. 2016). A evapotranspiração potencial (ETP) foi estimada pelo método proposto por de Thornthwaite e Mather (1955). 


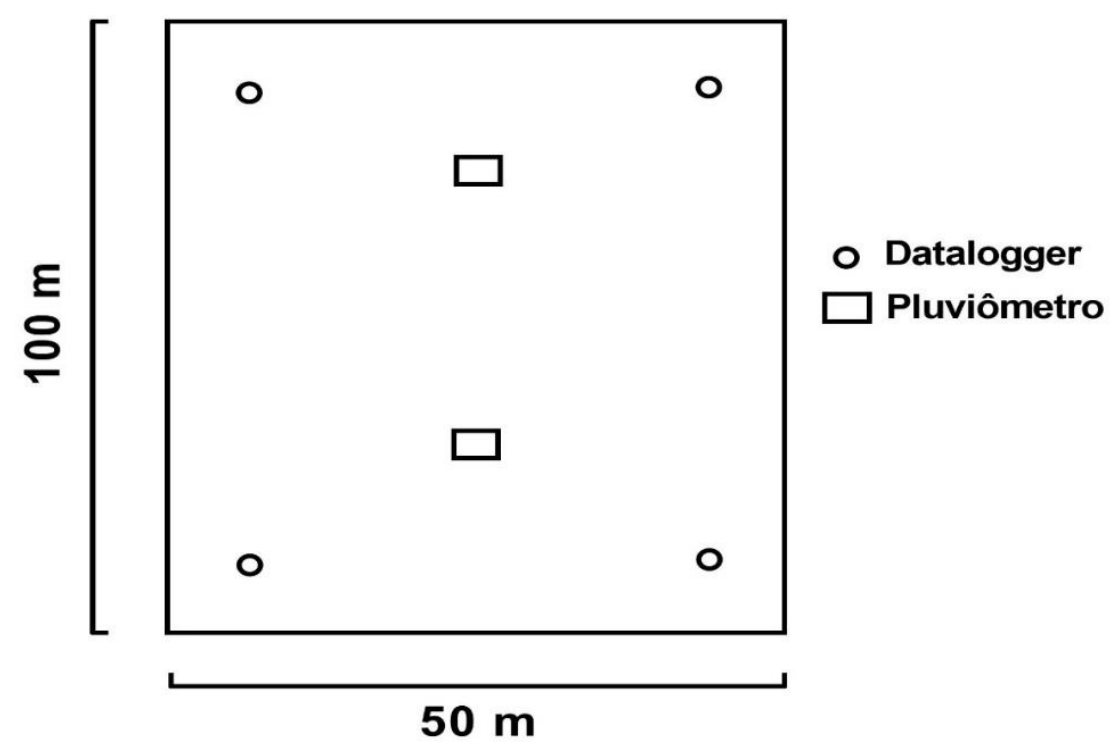

Figura 2. Distribuição espacial dos sensores para coleta de dados meteorológicos

Os valores de precipitação pluviométrica e evapotranspiração potencial foram utilizados para estimar a evapotranspiração real (ETR), o armazenamento de água no solo (ARM), a deficiência hídrica (DEF) e o excedente hídrico (EXC) no solo por diferença conforme Passos et al. (2016).

A partir dos dados históricos diários coletados determinou-se um indicativo de classificação climática proposto por Thornthwaite (1948), por ser o mais usual no âmbito agrícola (ROLIM et al., 2007). Realizou-se a estimativa do índice hídrico (Ih), que depende do EXC e da ETP total anual, do índice de aridez (Ia), a partir da relação entre a DEF e ETP total, do índice de umidade (Iu), calculado em função do Ih e do Ia e da ETP total anual e de verão. O índice hídrico (Ih), índice de aridez (Ia) e índice de umidade (Iu) foram calculados por meio das equações $1,2 \mathrm{e}$ 3 , respectivamente, sendo os resultados obtidos confrontados com os valores estabelecidos por Thornthwaite (1948), conforme Francisco et al. (2016).

$$
\mathrm{Ih}=\frac{\mathrm{EXC}}{\mathrm{ETP}} \mathrm{x}
$$

Em que:

$\mathrm{Ih}=$ índice hídrico $(\mathrm{mm})$;

$\mathrm{EXC}=$ excedente hídrico $(\mathrm{mm})$;
$\mathrm{ETP}=$ evapotranspiração total $(\mathrm{mm})$.

$$
\mathrm{Ia}=\frac{\mathrm{DEF}}{\mathrm{ETP}} \times 100
$$

Em que:

$\mathrm{Ia}=$ índice de aridez $(\mathrm{mm})$;

$\mathrm{DEF}=$ deficiência hídrica $(\mathrm{mm})$;

$\mathrm{ETP}=$ evapotranspiração total $(\mathrm{mm})$.

$\mathrm{Iu}=\mathrm{Ih}-0,6 \mathrm{x} \mathrm{IA}$

Em que:

$\mathrm{Iu}=$ índice de umidade ( $\mathrm{mm})$;

$\mathrm{Ih}=$ índice hídrico $(\mathrm{mm})$;

$\mathrm{Ia}=$ índice de $\operatorname{aridez}(\mathrm{mm})$.

Os dados foram submetidos ao teste de normalidade (Shapiro Wilks) e homocedasticidade (Levane). Quando satisfeitas estas pressuposições, efetuou-se a ANOVA seguida por comparação das médias pelo teste Tukey. Os dados que não cumpriram as pressuposições da ANOVA foram submetidos ao teste Kruskal-Wallis. Foi adotado um nível de 5\% para limite de significância em todos os testes.

\section{RESULTADOS E DISCUSSÃO}

O mês de setembro apresentou a temperatura média $\left(28,9^{\circ} \mathrm{C}\right)$ mais elevada, e 

maximus NO CERRADO MARANHENSE

os meses de janeiro e fevereiro, as médias mais baixas $\left(25,8\right.$ e $25,9^{\circ} \mathrm{C}$, respectivamente), durante o ano a temperatura apresentou baixa variabilidade temporal, sendo o valor médio anual estimado em $26,8{ }^{\circ} \mathrm{C}$. No entanto, a precipitação pluviométrica apresentou elevada variabilidade, evidenciando uma má distribuição pluviométrica do volume total de $1174,61 \mathrm{~mm}$, sendo os meses de janeiro e março com maiores volumes seguido pelo mês de fevereiro. A oscilação da precipitação pluviométrica demonstra grande irregularidade nos seus índices, devido à grande imprevisibilidade do volume de chuva, em virtude dos fatores meteorológicos atuantes no Meio Norte do Brasil, os quais ocasionam chuvas anômalas e de altas intensidades induzidas por fenômenos de larga escala la Niña (MEDEIROS, 2013) (Tabela 1).

Tabela 1. Balanço hídrico: temperatura $(\mathrm{T})$, precipitação pluviométrica $(\mathrm{P})$, evapotranspiração potencial (ETP) e evapotranspiração real (ETR) para uma área piloto sob cultivo convencional de pastagem Mombaça no cerrado maranhense.

\begin{tabular}{ccccc}
\hline Meses & $\mathrm{T}\left({ }^{\circ} \mathrm{C}\right)$ & $\mathrm{P}^{1}(\mathrm{~mm})$ & $\mathrm{ETP}(\mathrm{mm})$ & $\mathrm{ETR}(\mathrm{mm})$ \\
\hline Janeiro & $25,8 \mathrm{e} \pm 0,59$ & $202,7 \mathrm{a} \pm 124,63$ & $127,6 \mathrm{bc} \pm 8,52$ & $127,6 \mathrm{a} \pm 9,70$ \\
Fevereiro & $25,9 \mathrm{e} \pm 0,81$ & $171,3 \mathrm{~b} \pm 101,92$ & $116,2 \mathrm{c} \pm 9,38$ & $116,2 \mathrm{ab} \pm 8,50$ \\
Março & $26,1 \mathrm{de} \pm 0,69$ & $189,8 \mathrm{a} \pm 99,79$ & $130,4 \mathrm{bc} \pm 8,22$ & $130,4 \mathrm{a} \pm 8,78$ \\
Abril & $26,5 \mathrm{de} \pm 0,85$ & $122,1 \mathrm{c} \pm 79,02$ & $133,6 \mathrm{bc} \pm 8,94$ & $133,0 \mathrm{a} \pm 9,04$ \\
Maio & $26,8 \mathrm{~cd} \pm 0,84$ & $45,1 \mathrm{e} \pm 42,54$ & $141,3 \mathrm{bc} \pm 8,46$ & $100,2 \mathrm{bc} \pm 8,72$ \\
Junho & $26,2 \mathrm{de} \pm 1,28$ & $5,2 \mathrm{~g} \pm 9,75$ & $126,2 \mathrm{c} \pm 9,24$ & $29,1 \mathrm{~d} \pm 6,62$ \\
Julho & $26,4 \mathrm{de} \pm 0,85$ & $2,0 \mathrm{~g} \pm 6,50$ & $133,5 \mathrm{bc} \pm 8,68$ & $9,4 \mathrm{~d} \pm 8,86$ \\
Agosto & $27,6 \mathrm{bc} \pm 1,09$ & $3,6 \mathrm{~g} \pm 6,99$ & $156,9 \mathrm{ab} \pm 8,65$ & $5,8 \mathrm{~d} \pm 6,96$ \\
Setembro & $28,9 \mathrm{a} \pm 0,93$ & $26,4 \mathrm{f} \pm 30,56$ & $184,7 \mathrm{a} \pm 8,50$ & $26,9 \mathrm{~d} \pm 6,78$ \\
Outubro & $28,2 \mathrm{ab} \pm 1,14$ & $88,2 \mathrm{~d} \pm 55,54$ & $175,1 \mathrm{a} \pm 8,56$ & $88,3 \mathrm{c} \pm 8,32$ \\
Novembro & $26,8 \mathrm{~cd} \pm 1,02$ & $140,8 \mathrm{c} \pm 83,73$ & $142,4 \mathrm{bc} \pm 8,34$ & $140,8 \mathrm{a} \pm 6,92$ \\
Dezembro & $26,2 \mathrm{de} \pm 0,86$ & $177,3 \mathrm{~b} \pm 96,91$ & $135,3 \mathrm{bc} \pm 9,44$ & $135,3 \mathrm{a} \pm 8,36$ \\
\hline Total & 26,8 & 1174,61 & 1703,65 & 1043,12 \\
\hline
\end{tabular}

Médias de T, ETP e ETR seguidas pela mesma letra na coluna não diferem entre si pelo teste de Tukey, médias de P seguidas pela mesma letra na coluna não diferem entre si pelo teste Kruskal-Wallis. ${ }^{1}$ Dados não paramétricos.

Esse panorama estabelece duas épocas bem definidas durante o ano, uma "estação chuvosa" que se estende entre os meses de novembro a abril, a qual representa aproximadamente $85 \%$ do volume total da precipitação pluviométrica anual e uma "estação seca", correspondente ao período de maio a outubro, com aproximadamente $15 \%$, o que pode ser atribuído à posição geográfica da área (próximo à linha do equador), especialmente a baixa latitude e elevação.

Em seu estudo, Passos et al., (2016) usando dados da Estação climatológica convencional do INMET da estação meteorológica de Chapadinha observaram que duas estações bem definidas, uma chuvosa, que se estende ao longo dos meses de janeiro a maio, concentrando aproximadamente $84 \%$ do total acumulado, com índices de precipitação pluviométrica acima de $200 \mathrm{~mm}$ nestes meses, e a estação seca que ocorre entre os meses de junho a dezembro contribuindo com apenas $16 \%$ da precipitação, em relação ao total.

Resultados semelhantes foram reportados para o estado do Piauí por Lucena et al. (2016). Os autores relataram maiores volumes de precipitações para os meses de janeiro a abril, oscilando de 124,8 a 169,9 mm e os menores índices pluviométricos nos meses de junho a outubro, com oscilações de 1,6 a 17,2 mm. Esse corpo de evidências pode contribuir para compreender a variação sazonal na produção de forragem em sistemas de produção exclusivamente à pasto, sem sistema de irrigação complementar da lavoura.

A evapotranspiração potencial (ETP) anual foi estimada em $1703,65 \mathrm{~mm}$, sendo os meses com maiores médias setembro e outubro e os meses de fevereiro e junho com menores médias (Tabela 1). Entretanto, a evapotranspiração real (ETR) anual foi estimada em 1043,12 mm, sendo o mês de 
novembro com maior média $(140,8 \mathrm{~mm})$ e o mês de agosto de com a menor $(5,8 \mathrm{~mm})$ apesar do mês de agosto possuir uma temperatura média mensal elevada, o baixo valor na ETR é justificado pelo baixo volume de chuvas, o que proporciona falta de umidade no solo, os meses de junho e julho apresentaram uma discrepância considerável nos valores de ETR pelo mesmo motivo.

É possível perceber que no período de maior precipitação pluviométrica, ou seja, na "estação chuvosa" a evapotranspiração potencial (ETP) e a evapotranspiração real
(ETR) são relativamente iguais, porém na "estação seca" a ETR é consideravelmente menor que a ETP (Figura 3). Logo, implica-se dizer que durante o período da "estação chuvosa" foi atingido a evaporação máxima, principalmente devido à grande quantidade de água disponibilizada no solo pelo intenso volume de chuva nesse período, informação crucial para o manejo sustentável de pastagens. Ao longo do período da "estação seca" as taxas ETR e EVP são superiores aos índices pluviométricos, motivo da deficiência hídrica nesse período.

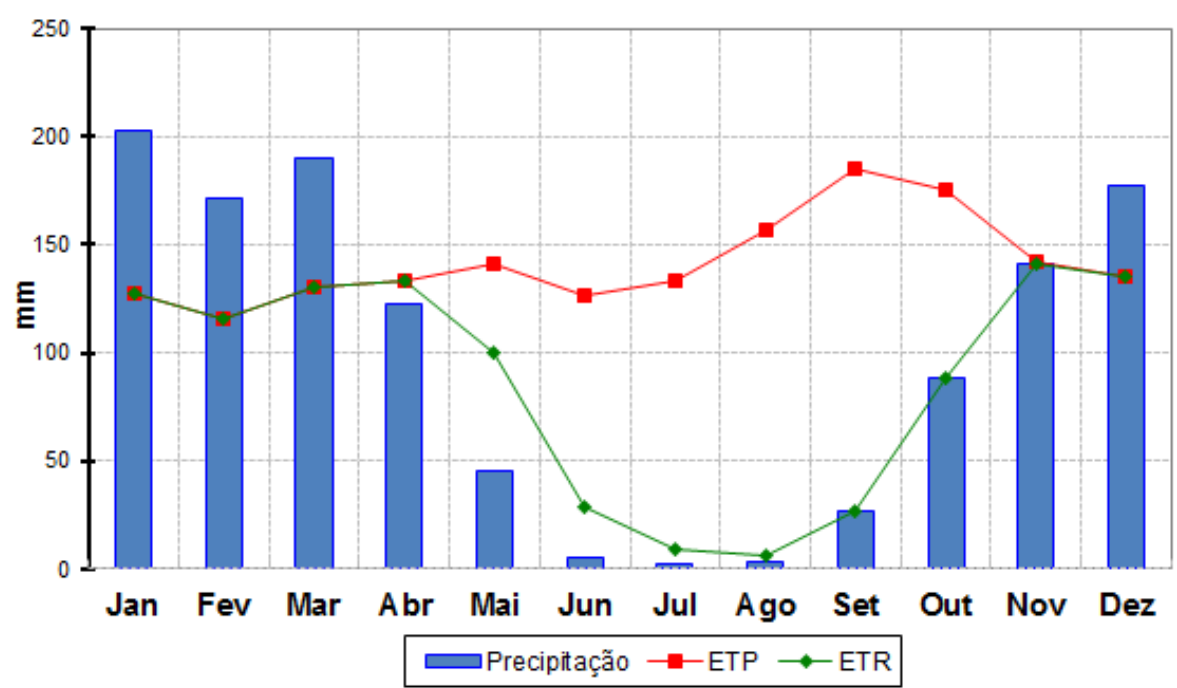

Figura 3. Representação gráfica do balanço hídrico para uma área piloto sob cultivo convencional de pastagem Mombaça no cerrado maranhense.

Estima-se uma deficiência hídrica (DEF) de $660,6 \mathrm{~mm}$ por ano, distribuído entre os meses de maio a outubro. Os meses com maior DEF foram setembro $(157,8 \mathrm{~mm})$ e agosto $(151,2 \mathrm{~mm})$. O período que abrange o mês de dezembro à meados de janeiro caracteriza-se como um período de reposição de água no solo. A última semana de janeiro a março configura-se como um período de excedente hídrico (EXC), com base na relação da precipitação pluviométrica coletada e a ETP e ETR estimadas. Tal comportamento está relacionado à precipitação pluviométrica, pois o volume de chuva foi significativamente superior nos meses com EXC (Figura 4).

Portanto, as chuvas do início da "estação chuvosa" são destinadas à reposição de água no solo. Quando o solo está plenamente abastecido, há um excedente de água no início na última semana de janeiro. Na estiagem, verifica-se nitidamente a retirada de água do solo, estendendo-se de abril a julho (Figura 4). Estas informações são importantes para a época de plantio (formação de pastos), definição da taxa de lotação do piquete, e práticas agrícolas como: adubação, calagem e atividades com implementos agrícolas.

É importante destacar que o processo de perda de água por evapotranspiração, ação conjunta da evaporação do solo e transpiração das plantas, é a variável que causa o maior impacto no ciclo hidrológico, além de ser o principal componente no balanço hídrico da agricultura (CARVALHO et al., 2015). 

maximus NO CERRADO MARANHENSE

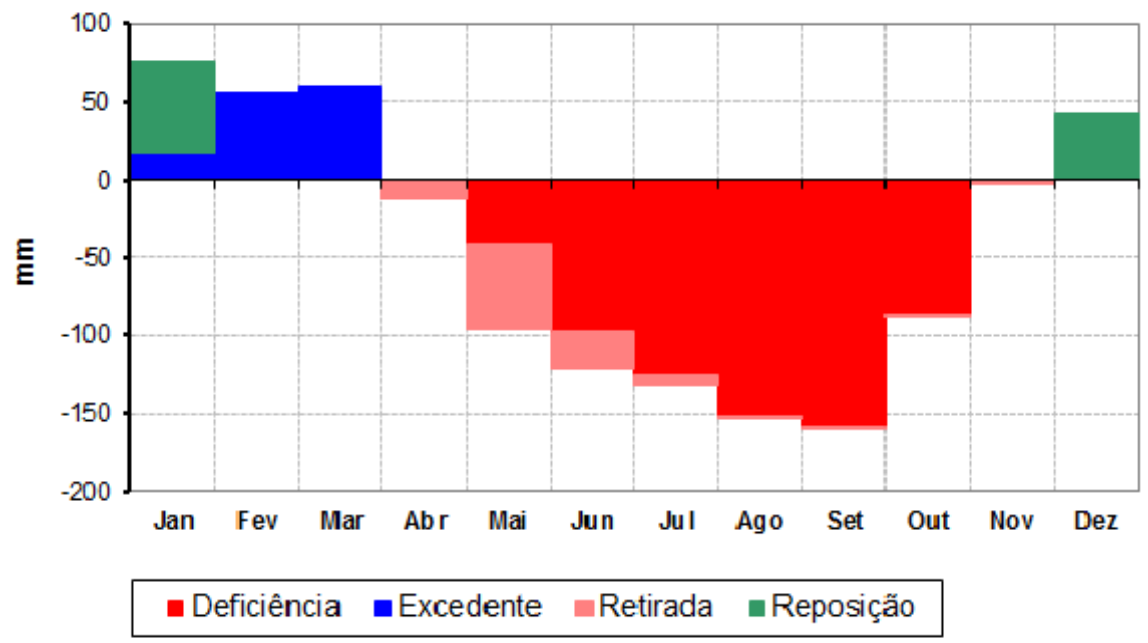

Figura 4. Deficiência, excedente, retirada e reposição hídrica ao longo do ano para uma área piloto sob cultivo convencional de pastagem Mombaça no cerrado maranhense.

Portanto, é um parâmetro essencial nos estudos de avaliação de qualidade ambiental nas lavouras, pastagens e para o manejo de bacias hidrográficas, de forma a garantir maior eficiência no uso dos recursos hídricos.

Os valores obtidos para o índice hídrico (Ih), o índice de aridez (Ia) e índice de umidade (Iu), utilizados para obter um indicativo de classificação climática, foram respectivamente de 7,$71 ; 38,8$ e $-15,54 \mathrm{~mm}$. Logo, há fortes indícios que o clima da área em estudo enquadra-se na tipologia $\mathrm{C} 1$, o que indica clima sub úmido seco. O subtipo, com base no Ia $(38,8 \mathrm{~mm})$, é classificado como $\mathrm{S} 2$, o que indica grande deficiência hídrica no verão. O fator térmico é classificado como "A", ou seja, megatérmico, uma vez que a evapotranspiração potencial (ETP) foi estima em 1703,66 mm, superior aos $1140 \mathrm{~mm}$ (Tabela 1). A relação percentual entre a ETP período quente (maio a outubro) com evapotranspiração anual foi de $32 \%$, ou seja, classificada no subtipo a'. Sendo assim a fórmula completa segundo Thonthwaite é C1S2A a, ou seja, subsumido seco, megatérmico com grande deficiência hídrica no inverno.

\section{CONCLUSÕES}

Há uma distribuição sazonal das chuvas com dois períodos climáticas definidas, sendo o período chuvoso de novembro a abril, nos meses de maio a outubro (período seco), deve adotar estratégias alimentares alternativas, como fenação, silagem, confinamento ou irrigação da pastagem, uma vez que ocorre um déficit na produção de biomassa na pastagem. A precipitação pluviométrica anual mais provável é 1174,6 $\mathrm{mm}$, com excedente hídrico no final de janeiro a março e um período de deficiência hídrica de maio a outubro.

\section{AGRADECIMENTO}

Ao professor Dr. Celso Yoji Kawabata (in memoriam) pela idealização e imensa contribuição na realização deste trabalho.

\section{REFERÊNCIAS BIBLIOGRÁFICAS}

ANDRADE, W.R.; SILVA，M.F.; PORTO, E.M.V.; VITOR, C.M.T.; PINTO, F.S. Densidade Populacional de perfilhos de cultivares de Brachiaria Brizantha submetidas a doses crescentes de nitrogênio. $\mathbf{5}^{\circ}$ Fórum de Ensino, Pesquisa, Extensão e Gestão (FEPEG), Universidade Estadual de Montes Claros, 2011.

CARNEIRO, J. S. S.; SILVA, P. S. S.; SANTOS, A. C. M.; FREITAS, G. A.; 
SILVA, R. R. Respostas do capim Mombaça sob efeito de fontes e doses de fósforo na adubação de formação. J. Journal of bioenergy and food science, Macapá, v.4, n,1, p12-25, 2017.

CARVALHO, D. F.; ROCHA, H. S.; BONOMO, R.; SOUZA, A. P. Estimativa da evapotranspiração de referência a partir de dados meteorológicos limitados. Pesquisa Agropecuária Brasileira, Brasília, v. 50, n. 1, p. 1-11,jan. 2015. https://doi.org/10.1590/S0100204X201500010 0001 .

CARVALHO, I. S. H. A pecuária geraizeira e a conversação da biodiversidade no cerrado do Norte de Minas. Sustentabilidade em Debate, Brasília, v.5, n.3, p.19-36, 2014.

FRANCISCO, P. R. M.; MEDEIROS, R. M.; SANTOS, D.; MATOS, R. M. Classificação Climática de Köppen e Thornthwaite para o Estado da Paraíba. Revista Brasileira de Geografia Física, Recife, v.9, n.4, p. 10061016, 2015.

FRANCISCO, P. R. M.; SANTOS, D.; BANDEIRA, M. M.; GUIMARÃES, C. L.; CABRAL, D. E. C. Aptidão climática do sorgo (Sorguhum bicolor) para o estado da Paraíba, Brasil. Revista Brasileira de Geografia Física, Recife, v.9, n.4, p. 10431057, 2016.

LUCENA, D.B., MEDEIROS, R.M., SABOYA, L.M.F., NASCIMENTO, P.L. Aptidão e zoneamento agroclimático da palma forrageira para o Estado do Piauí. Revista Brasileira de Agricultura Irrigada, Fortaleza, v.10, n.4, p. 809-819, 2016

MARANHÃO - GOVERNO DO ESTADO DO MARANHÃO. Gerência de Planejamento e Desenvolvimento Econômico - GEPLAN. Atlas do Maranhão. São Luís: Universidade Estadual do Maranhão, 39 p. 2002.

MATOS, R. M.; SILVA, J. A. S.; MEDEIROS, R. M. Aptidão climática para a cultura do feijão caupi do município de Barbalha - CE. Revista Brasileira de Agricultura Irrigada, Fortaleza, v.8, n.6, p.422-431, 2014.

MEDEIROS, R. $\quad$ M. Estudo agrometeorológico para o Estado da Paraíba. Ed. Avulsa, 2013, p. 138.

MEDEIROS, R. M.; FRANCISCO, P. R. M.; SANTOS, D. Balanço hídrico e erosividade em função das mudanças climáticas no estado da Paraíba. Revista Brasileira de Geografia Física, Recife, v.8, n.4, p. 1068-1084, 2015.

MEDEIROS, R. M.; SANTOS, D. C. dos; SOUSA, F. A. S.; GOMES FILHO, M. F. Análise Climatológica, classificação climática e variabilidade do balanço hídrico climatológico na Bacia do Rio Uruçuí Preto, PI. Revista Brasileira de Geografia Física, Recife, v.6, n.4, p.652-664, 2013.

PASSOS, M. L. V.; RAPOSO, A. B.; MENDES, T. J. Estimativa da distribuição da precipitação pluviométrica provável em diferentes níveis de probabilidade de ocorrência. Revista Brasileira de Agricultura Irrigada, Fortaleza, v.11, n.1, p.1016-1115, 2017.

PASSOS, M. L. V.; ZAMBRZYCKI, G. C.; PEREIRA, R. S. Balanço hídrico e classificação climática para uma determinada região de Chapadinha-MA. Revista Brasileira de Agricultura Irrigada, Fortaleza, v.10, n.4, p. $758-766,2016$.

ROLIM, G.S.; CAMARGO, M.B.P.; LANIA, D.G.; MORAES, J.F.L. Classificação climática de Köppen e de Thornthwaite e sua aplicabilidade na determinação de zonas agroclimáticas para o estado de São Paulo. Bragantia, Campinas, v.66, n.4, p.711-720, 2007.

SANTOS, R.B.; SOUZA, A.P.; SILVA, A.C.; ALMEIDA, F.T.; ARANTES, K.R.; SIQUEIRA, J.L. Planejamento da pulverização de fungicidas em função das 
variáveis meteorológicas na região de Sinop MT. Global Science and Technology, Goiânia, v.6, n.1, p.72-88, 2013.

SOUZA, A. P.; MOTA, L. L.; ZAMADEI, T.; MARTIM, C. C.; ALMEIDA, F. T.; PAULINO, J. Classificação climática e balanço hídrico climatológico no estado de Mato Grosso. Pesquisa Agrárias e Ambientais, Cuiabá, v.1, n.1, p. 34-43, 2013.
THORNTHWAITE, C. W. An approach towards a rational classification of climate. Geographical Review, London, v.38, p.55-94, 1948.

THORNTHWAITE, C. W.; MATHER, J. R. The water balance. Publications in Climatology. New Jersey: Drexel Institute of Technology p.104, 1955. 